\title{
Molecular Docking of Polyphenol Compounds from Anacardium occidentale with Alpha-Glucosidase and Dipeptidyl- Peptidase-4 Enzymes
}

\author{
Normah Haron ${ }^{a, *}$, Norsyarina Nadiaa, Puteri Nur Farahin ${ }^{a}$, Deny Susanti ${ }^{b}$, \\ Noor Hasnizaa ${ }^{a}$ Khairul Bariyyah Abd Halim ${ }^{a}$ \\ aDepartment of Biotechnology, Kulliyyah of Science, International; Islamic University \\ Malaysia, 25200 Kuantan, Pahang, Malaysia; 'Department of Chemistry, Kulliyyah \\ of Science, International Islamic University Malaysia, 25200 Kuantan, Pahang, \\ Malaysia
}

Abstract Type 2 diabetes mellitus (T2DM) is a chronic disease, in which the body failed to regulate blood glucose level due to insulin resistance. This condition may lead to high glucose level, which could potentially causes many serious health problems associated with cardiovascular system, nerve, eye and kidney. In treatment of T2DM, enzymes such as alphaglucosidase (AG) and dipeptidyl-peptidase IV (DPP-4) have become the main targets since these enzymes play important roles in controlling the blood glucose level in the human body. In this study, the computational approach using molecular docking simulation study was used to predict the interaction and binding affinity of polyphenol compounds from Anacardium occidentale ( $A$. occidentale) towards the AG and DPP-4 enzymes. The results were analysed based on three parameters: binding energy value, hydrogen bond formation and hydrophobic interaction between the compound and the protein at the binding site. The result showed that myricetin interacted with AG with the lowest binding energy of $-7.6 \mathrm{kcal} / \mathrm{mol}$ and formed only one hydrogen bond to the Asp327 residue. In contrast, acarbose the positive control, interacted with many residues such as Asp327, Asp443 and Asp542 with the binding energy of $-6.0 \mathrm{kcal} / \mathrm{mol}$. As for DPP-4 enzyme, sitagliptin was predicted as the best binder out of 15 polyphenols with binding energy of -9.2 $\mathrm{kcal} / \mathrm{mol}$. At the DPP-4 enzyme druggable region, sitagliptin formed an interaction with Tyr547 residue. In conclusion, our result suggested alpha-glucosidase as the most promising enzyme interacted with polyphenol compounds with favourable inhibitory effect since it can interact better than the current anti-diabetic drug, acarbose.

${ }^{*}$ For correspondence: normahh@iium.edu.my

Received: 19 Nov 2020 Accepted: 19 Feb 2021

(C) Copyright Normah et al. This article is distributed under the terms of the Creative Commons Attribution License, which permits unrestricted use and redistribution provided that the original author and source are credited.
Keywords: Molecular docking, Type 2 Diabetes Mellitus, Anacardium occidentale, enzymes, acarbose.

\section{Introduction}

Diabetes mellitus is a disease where the insulin, a hormone to control the blood glucose level is secreted insufficiently by the pancreas or the state that the body unable to use the secreted insulin efficiently causing a high glucose level in the bloodstream [31]. According to the World Health Organization [31], diabetes mellitus is the ninth leading cause of death in 2019 which recorded the death of 12.9 per 100000 populations in Malaysia. There are two main types of diabetes mellitus, which are Type 1 Diabetes Mellitus (T1DM) and Type 2 Diabetes Mellitus (T2DM). T2DM is one of the common health problems faced by the people worldwide due to the resistance of insulin by the body to control the blood glucose level which leads to many serious health problems such as nerve and kidney damages, eye problems and cardiovascular diseases. Therefore, the research regarding T2DM has drawn many attentions of the 
researchers around the world in developing an anti-diabetic drug to treat this inherited disease.

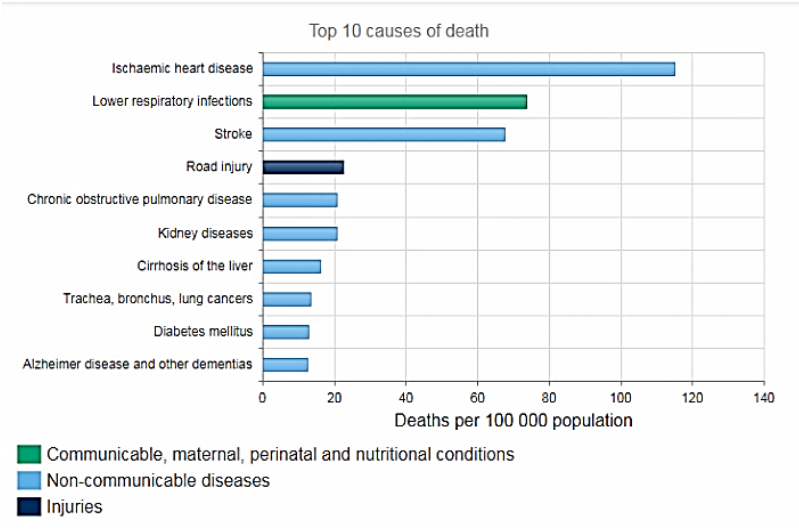

Figure 1: Rank of diabetes mellitus disease in the top ten Malaysia causes of deaths in 2019 [31].

As for the treatment of T2DM, alpha-glucosidase (AG) and dipeptidyl-peptidase IV (DPP-4) have been one of the main targets since these enzymes play important roles in controlling the blood glucose level in the human body. Many anti-diabetic drugs such as acarbose and sitagliptin have been clinically used to treat the patients with T2DM by inhibiting the activity of AG and DPP-4 enzymes, respectively [15]. However, these drugs are known to have some side effects to the patients such as stomach pain and diarrhea. Therefore, the potential therapeutic effects of the natural compounds from the plants with minimum side effects are widely being studied.

In recent years, the interest in discovering and researching the health benefits provided by the plant products has grown over the past decades [32]. Indeed, it has been scientifically proven that many of herbal plants could be utilized as an alternative medicine in the prevention and management of T2DM as they possess anti-hyperglycemic, anti-hyperlipidemic and antioxidant properties [2, 18, 24]. A. occidentale shoots extract has been reported to contain several total phenolic compounds such as flavonoids, anthocyanins and tannins that are recognized for the treatment of several conditions including cardiovascular diseases [6]. As mentioned by Okpashi et al. [23] in their studies, $A$. occidentale shoots extract has antidiabetic, antibacterial, anti-inflammatory, and antiulcerogenic properties. Therefore, 15 polyphenol compounds from $A$. occidentale namely caffeic acid, salicylic acid, sinapic acid, catechin, genistein, robustaflavone, kaemferol, quercetin, myricetin, apigenin, vanillic acid, gallic acid, ferulic acid, protocatechuic acid and $\rho$-coumaric acid were selected in this study and its binding interaction with the targeted enzymes associated with T2DM was studied using molecular docking approach.

Computer-aided drug design (CADD) is one of the effective methods to identify potential lead compounds for the developments of possible drugs for a wide range of diseases [5]. It is a valuable tool for screening new compounds as potential diabetic enzymes inhibitors. Molecular docking can be defined as a computational process commonly utilized for rapidly predicting the binding modes and affinities of small molecules against their target molecules (usually proteins) in a non-covalent fashion [5]. Molecular docking procedures have been extensively used to predict the binding affinity against many diabetic target enzymes such as aldose reductase, glucokinase, fructose-6-phosphate amidotransferase and pyruvate dehydrogenase kinase isoform 2 [3, 10, 12, 19]. Recently, an in vitro study by Nur Athirah Zabidi et al. [21] had demonstrated that inhibition of DPP-IV and AG can help stimulate the secretion of insulin and reduce glucose level in the bloodstream. Thus, both of these enzymes may be targeted for designing more potent anti-diabetic drugs.

This study aims to predict the binding interaction and to explore the binding mode of polyphenol compounds from $A$. occidentale with $A G$ and DPP-4 enzymes by using molecular docking simulation technique. Here, the interactions between the polyphenol compounds from $A$. occidentale with $A G$ and DPP-4 enzymes were assessed by evaluating the binding energy, the formation of the hydrogen bond, electrostatics and hydrophobics with the active site residues of both target proteins. This study improves understanding of the ligand interaction with the target proteins, in which it provides the potential binding modes and binding interaction which could be further exploited computationally and experimentally as the potential inhibitor for diabetic enzymes of potential targets for future new anti-diabetic drug design. 


\section{Materials and Methods}

The crystal structure AG and DPP-4 enzymes were retrieved from Protein Database while the structure of polyphenol compounds was retrieved from Pubchem database. Bioinformatics tools such as AutoDock 4.2 and AutoDock Vina software were utilised to perform the molecular docking simulation to gain insight on the interaction that occurred between polyphenol compounds and the enzymes. The docking results were then analysed using different software such as AutoDock 4.2, PyMOL and Ligplot. Besides, the workstation was well-equipped with a computer which its processor was Intel@ Core ${ }^{\mathrm{TM}} \mathrm{i5}-4590 \mathrm{CPU} @$ 3.30GHz $\times 4$ while its Operating System (OS) was Ubuntu 16.04 LTS.

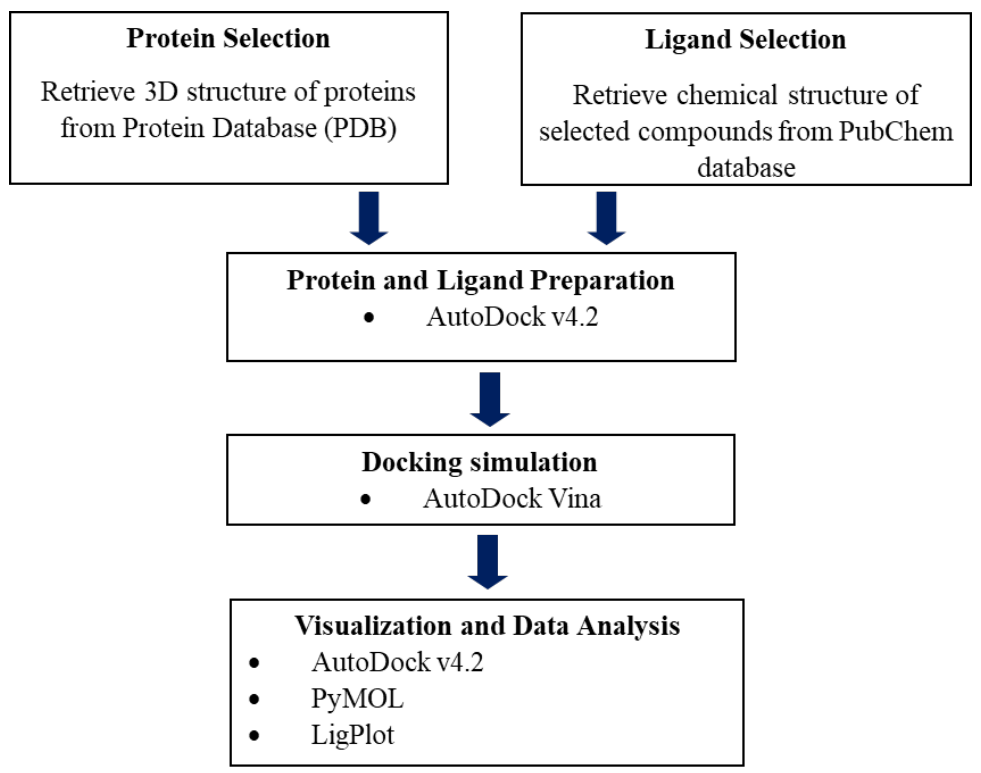

Figure 2. Workflow for the computational study of protein-ligand interaction

\section{Protein preparation}

Three-dimensional (3D) structure of the two target proteins related to diabetes which are AG and DPP4 enzymes were retrieved from Protein Data Bank (PDB) database with PDB ID 2QMJ and 2ONC, respectively, and were saved in PDB file format. As shown in Figure 3, both enzymes were in the complex form which AG enzyme was in complex with acarbose while DPP-4 enzyme was in a complex with alogliptin. Only the protein was used in this study. At the same time, all crystal water and heteroatoms such as acarbose and alogliptin were removed from the protein structure.

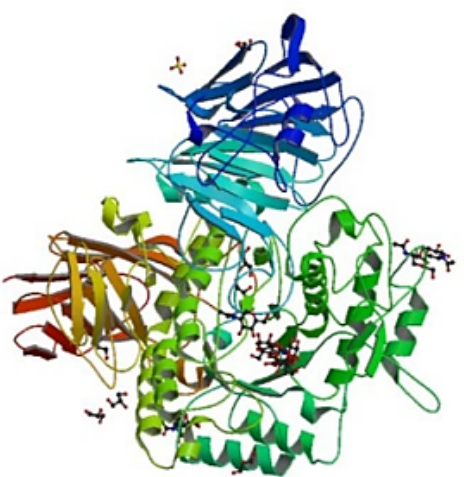

A

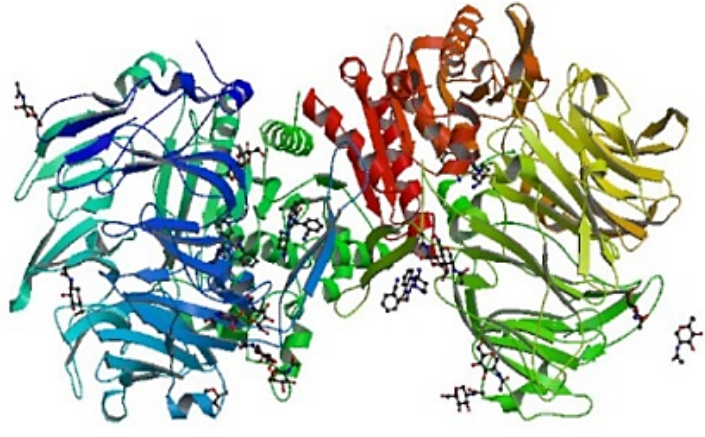

$\mathrm{B}$

Figure 3. The 3-D structure of diabetic enzymes retrieved from the PDB database. (A) AG enzyme in complex with acarbose (Representation: Cartoon $=$ AG enzyme, Stick $=$ Acarbose). $(B)$ DPP-4 enzyme in complex with alogliptin (Representation: Cartoon = DPP-4 enzyme, Stick = Alogliptin). 


\section{Ligand preparation}

An earlier study by Abdullah Thaidi et al. [1] had reported a positive inhibition effect on a-amylase and DPP-4 enzymes by using the crude extract of $A$. occidentale shoots, and had been analysed using high performance liquid chromatography (HPLC) to contain phenolic acids and flavonoids compounds which were gallic acid, ferulic acid, quercetin, kaempferol and p-coumaric acid. Besides, other studies had also mentioned the presence of polyphenol compounds in the $A$. occidentale which are caffeic acid, salicylic acid, sinapic acid, catechin, genistein, robustaflavone, myricetin, apigenin, vanillic acid and protocatechuic acid [1, 4, 8-9, 25-27]. Thus, a total of 15 polyphenols from $A$. occidentale namely caffeic acid, salicylic acid, sinapic acid, catechin, genistein, robustaflavone, kaemferol, quercetin, myricetin, apigenin, vanillic acid, gallic acid, ferulic acid, protocatechuic acid and $\rho$-coumaric acid were selected to conduct this current study and predict for future reference. The chemical structure of each polyphenol compound was retrieved from PubChem compound database and saved as Structure Date File (SDF) format, which then converted into PDB file format using PyMOL. Figure 4 shows the chemical structure of all compounds used in this study.<smiles>O=C(O)/C=C/c1ccc(O)c(O)c1</smiles><smiles>[C+]1C=CC=C1</smiles><smiles>O=C(O)c1ccccc1O</smiles><smiles>COc1cc(/C=C/C(=O)O)cc(OC)c1O</smiles><smiles>Oc1cc(O)c2c(c1)O[C@H](c1ccc(O)c(O)c1)[C@H](O)C2</smiles><smiles>O=c1c(-c2ccc(O)cc2)coc2cc(O)cc(O)c12</smiles><smiles>O=c1cc(-c2ccc(O)c(-c3c(O)cc4oc(-c5ccc(O)cc5)cc(=O)c4c3O)c2)oc2cc(O)cc(O)c12</smiles><smiles>O=c1c(O)c(-c2ccc(O)cc2)oc2cc(O)cc(O)c12</smiles><smiles>O=c1c(O)c(-c2ccc(O)c(O)c2)oc2cc(O)cc(O)c12</smiles><smiles>[CH]1CCC1</smiles><smiles>O=c1c(O)c(-c2cc(O)c(O)c(O)c2)oc2cc(O)cc(O)c12</smiles><smiles>O=c1cc(-c2ccc(O)cc2)oc2cc(O)cc(O)c12</smiles>

\section{$\mathrm{k}$}<smiles>COc1cc(C(=O)O)ccc1O</smiles>

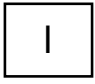<smiles>O=C(O)c1cc(O)c(O)c(O)c1</smiles><smiles>COc1cc(/C=C/C(=O)O)ccc1O</smiles><smiles>O=C(O)c1ccc(O)c(O)c1</smiles>

\section{0}<smiles>O=C(O)/C=C/c1ccc(O)cc1</smiles>

Figure 4. Chemical structure of 15 natural polyphenol compounds from $A$. occidentale retrieved from PubChem database. (a) Caffeic acid, (b) Salicylic acid, (c) Sinapic acid, (d) Catechin, (e) Genistein, (f) Robustaflavone, (g) Kaempferol, (h) Quercetin, (i) Myricetin, (j) Apigenin, (k) Vanillic acid, (l) Gallic acid, (m) Ferulic acid, (n) Protocatechuic acid, (o) P-coumaric acid. 
esides, two types of synthetic drug compounds, acarbose and sitagliptin, which acted as AG and DPP4 inhibitors, respectively were used as a control to analyse the interaction between the polyphenol compounds from $A$. occidentale and the targeted enzymes. These two chemical structures were also retrieved from PubChem database [20] and showed in Figure 5.

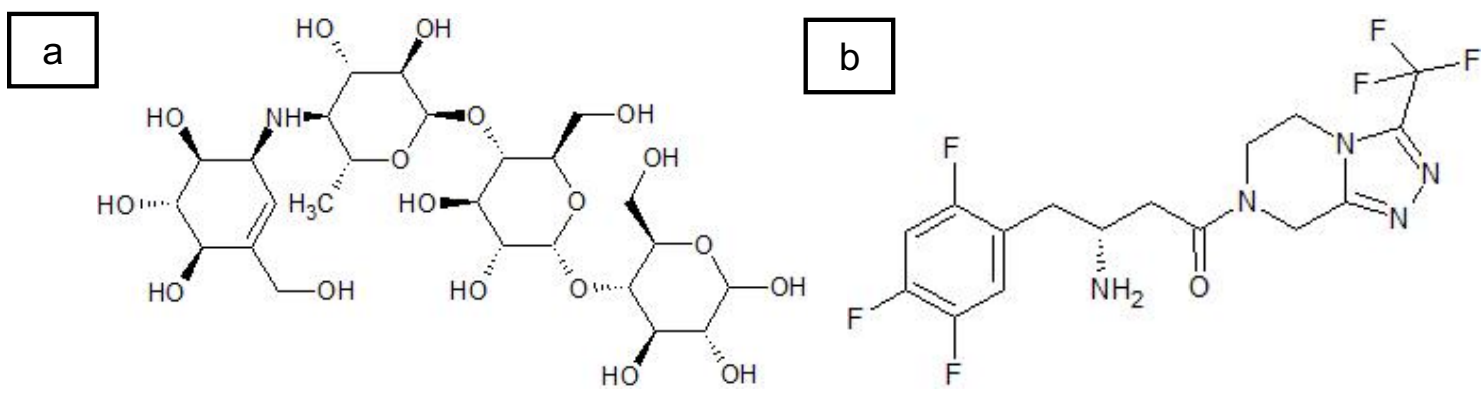

Figure 5. 2D structures of (a) acarbose and (b) sitagliptin retrieved from Pubchem database respectively

\section{Molecular docking of polyphenol compounds with AG and DPP-4 enzymes}

AutoDock Vina program was used to run docking simulation. A total of 15 polyphenol compounds from A. occidentale were docked with AG and DPP-4 enzymes at the binding site. Then, as a control, acarbose and sitagliptin each was docked to AG and DPP-4 enzymes respectively. The docking coordinate and parameter file for proteins and ligands were prepared by using Autodock 4.2 version. The preparation of the coordinate file included the addition of hydrogen atoms, Kollman charges and Gasteiger charge to the protein or target receptor [28]. Then, the output file for the protein was saved in PDBQT file format. Next, the grid boxes with the size $20 \times 24 \times 24$ and $24 \times 20 \times 26$ were set using AutoGrid on AG and DPP-4 enzymes respectively, which covered all the targeted binding site regions which the ligand was supposed to bind. The grid spacing was $1.000 \AA$ and the search was based on the Lamarckian Genetic Algorithm to search the best conformer [28]. As for ligands, all compounds were assigned with Gasteiger charges and saved as PDBQT file format [14]. As all the coordinate files for protein and ligands were prepared, the docking simulation was run using AutoDock Vina program which the protein was treated as a rigid body. In contrast, the ligand was flexible during the docking process. Based on the docking result, the binding energy of the protein-ligand complexes was evaluated.

\section{Visualisation and analysis}

The result of molecular docking was analysed using different software such as AutoDock 4.2, PyMOL and LigPlot program. PyMOL program was mainly used for visualisation of the structures. The main parameters for molecular docking analysis were the binding energy values of the protein-ligand interaction, hydrophobic interaction and the number of hydrogen bond formation. The binding energy value for each compound was shown as a result of molecular docking and the best interacting compound of both enzymes was selected. Besides, the number of hydrogen bonds formation and the residues that formed the hydrogen bonds with the ligand were identified using AutoDock 4.2 software. The distance of hydrogen bonding between the ligand and the interacting residue was being calculated using PyMOL. Also, AutoDock 4.2 software was used to reveal all the interacting residues of the protein, and each ligand; meanwhile, Ligplot software was used to visualise the hydrophobic interaction of the protein and the ligands.

\section{Results and Discussion}

Molecular docking simulation is essential especially for the screening of potential new drug compounds. The results from our molecular docking simulation of polyphenol compounds with AG and DPP-4 enzymes were compared with the commercial AG inhibitor, acarbose and DPP-4 inhibitor, sitagliptin to evaluate the potential of natural polyphenol compounds as the new inhibitor for both enzymes. Apart from that, the result of molecular docking of polyphenol compounds with AG and DPP-4 enzymes were analysed to predict the most promising enzyme which shown the best interaction with polyphenol compounds. 


\section{Molecular docking analysis of AG enzyme with polyphenol compounds}

The first parameter in molecular docking study was the value of binding energy predicted by Autodock for AG and polyphenol compound complexes. The results of the molecular docking for each complex were showed in Table 1, with their corresponding binding energy values. The resulted binding energies were used for the binding affinity prediction of the complexes to determine the best polyphenol compound that formed the most favourable interactions with AG. Besides, the value of binding energy was used as an indicator of the binding affinity of the complexes.

Table 1. The binding energy of AG enzyme with 15 polyphenol compounds and acarbose from the lowest to the highest values.

\begin{tabular}{|c|c|c|}
\hline No. & Polyphenol compounds & Binding energy $(\mathrm{kcal} / \mathrm{mol})$ \\
\hline 1 & Myricetin & -7.6 \\
\hline 2 & Quercetin & -7.5 \\
\hline 3 & Apigenin & -7.5 \\
\hline 4 & Kaempferol & -7.4 \\
\hline 5 & Catechin & -7.4 \\
\hline 6 & Genistein & -7.1 \\
\hline 7 & Caffeic acid & -6.3 \\
\hline 8 & Salicylic acid & -6.2 \\
\hline 9 & Gallic acid & -6.0 \\
\hline 10 & $\rho$-coumaric acid & -6.0 \\
\hline 11 & Protocatechuic acid & -5.9 \\
\hline 12 & Ferulic acid & -5.9 \\
\hline 13 & Sinapic acid & -5.7 \\
\hline 14 & Vanillic acid & -5.6 \\
\hline 15 & Robustaflavone & -3.6 \\
\hline 16 & Acarbose (control) & -6.0 \\
\hline
\end{tabular}

As mentioned by Kondo et al. [17], the binding energy consists of positive and negative values which the positive value refers to the complex binding destabilisation while the negative value indicates the complex binding stabilisation. Based on the result in Table 1, it showed that the binding energy values for all complexes were negative that the stabilisation of complex binding had occurred and the polyphenol compounds were all favourable towards the targeted binding site of $A G$ enzyme. Besides, the molecular docking simulation of 15 polyphenol compounds and acarbose with AG enzyme revealed some of the polyphenol compounds with lower binding energy compared to acarbose which were myricetin, quercetin, apigenin, kaempferol, catechin, genistein, caffeic acid and salicylic acid with the binding energy of $-7.6 \mathrm{kcal} / \mathrm{mol},-7.5 \mathrm{kcal} / \mathrm{mol},-7.5 \mathrm{kcal} / \mathrm{mol},-7.4 \mathrm{kcal} / \mathrm{mol},-7.4 \mathrm{kcal} / \mathrm{mol},-7.1 \mathrm{kcal} / \mathrm{mol},-6.3$ $\mathrm{kcal} / \mathrm{mol}$ and $-6.2 \mathrm{kcal} / \mathrm{mol}$, respectively as compared to acarbose which was $-6.0 \mathrm{kcal} / \mathrm{mol}$. There was only a slight difference in the binding energy value of all complexes except for AG-robustaflovone complex.

Among these complexes, AG-myricetin complex had the lowest binding energy value which was the best possible ligand that formed a complex with $A G$ enzyme. It was due to the lower the value of binding energy, the greater the binding affinity of the protein-ligand complex which indicated the stronger interaction of the complex binding. Thus, it emphasised that myricetin bound to AG binding site was stronger than the acarbose. This result suggested that myricetin is the best binder to AG and could potentially be a good drug candidate against this enzyme. In contrast, AG-robustaflavone had the highest value for binding energy which was $-3.6 \mathrm{kcal} / \mathrm{mol}$, and it showed that robustaflavone has less binding affinity towards $A G$.

\section{Formation of the hydrogen bond between AG enzyme and polyphenol compounds}

The second parameter for molecular docking analysis was the formation of hydrogen bonds. AutoDock v4.2 and PyMOL was used to observe the presence of hydrogen bonding formed by the AG-myricetin complex and AG-acarbose complex. PyMOL software measured the distance of the hydrogen bond meanwhile AutoDock v4.2 software calculated the number of hydrogen bond formed by the complexes and showed the residues of protein that formed a hydrogen bond with the compound. According to Berg, Tymoczko and Stryer [7], the most favourable distance for hydrogen bond was between 1.5-2.6 $\AA$ 
approximately. Besides, the strength of the hydrogen bond interaction was determined by its bond distance. The shorter the length of hydrogen bond formed by each complex would indicate the greater of the binding affinity of the complex hence it had a stronger interaction of the protein-ligand complex. If the distance of hydrogen bond formed by the complex binding is exceeded $3.0 \AA$, the hydrogen bond would be assumed to have a weak interaction and it could be easily disrupted [29]. Also, Hubbard [13] stated that the energy provided by a single hydrogen bond was 20 to $25 \mathrm{~kJ} / \mathrm{mol}$ approximately, which contributed to the protein structure stability. Table 2 showed the number of hydrogen bond formation and the interacting residues for each complex that were analysed using AutoDock v4.2 and the distance of hydrogen bond formation which was measured using PyMOL.

Table 2. Hydrogen bond formation and interacting residues of $A G$ enzyme with each polyphenol compound that were analysed by Autodock v4.2 and PyMOL.

\begin{tabular}{|c|c|c|c|c|c|}
\hline No. & $\begin{array}{l}\text { Polyphenol } \\
\text { compounds }\end{array}$ & Interacting residues & $\begin{array}{l}\text { No. of } \mathrm{H}- \\
\text { bond }\end{array}$ & $\mathrm{H}$-bonded residue & Distance $(\AA)$ \\
\hline 1 & Myricetin & $\begin{array}{c}\text { Tyr299, Asp327, Trp406, Asp542, } \\
\text { Phe575 }\end{array}$ & 1 & Asp327 & 2.0 \\
\hline 2 & Quercetin & $\begin{array}{l}\text { Tyr299, Met444, Arg526, Phe575, } \\
\text { Gln603, Tyr605 }\end{array}$ & 3 & $\begin{array}{l}\text { Arg526 } \\
\text { GIn603 } \\
\end{array}$ & $\begin{array}{c}2.0 \\
2.0,2.1 \\
\end{array}$ \\
\hline 3 & Apigenin & $\begin{array}{c}\text { Tyr299, Met444, Arg526, Asp542, } \\
\text { Phe575, GIn603, Tyr605 }\end{array}$ & 2 & $\begin{array}{l}\text { Arg526 } \\
\text { Asp542 }\end{array}$ & $\begin{array}{l}3.0 \\
2.2 \\
\end{array}$ \\
\hline 4 & Kaempferol & $\begin{array}{c}\text { Tyr299, Asp443, Met444, Arg526, } \\
\text { Phe575, GIn603, Tyr605 }\end{array}$ & 2 & $\begin{array}{l}\text { Arg526 } \\
\text { Asp443 }\end{array}$ & $\begin{array}{l}2.9 \\
2.2 \\
\end{array}$ \\
\hline 5 & Catechin & $\begin{array}{c}\text { Tyr299, Met444, Arg526, Asp542, } \\
\text { Phe575, GIn603, Tyr605 }\end{array}$ & 1 & Arg526 & 3.0 \\
\hline 6 & Genistein & $\begin{array}{c}\text { Tyr299, Trp406, Met444, Phe450 Arg526, } \\
\text { Phe575 }\end{array}$ & 1 & Arg526 & 2.8 \\
\hline 7 & Caffeic acid & $\begin{array}{l}\text { Glu182, His183, Val184, Pro206, Leu213, } \\
\text { Leu540, Asn543, Asp549, Gly556, Phe560 }\end{array}$ & 2 & $\begin{array}{l}\text { Glu182 } \\
\text { Asn543 }\end{array}$ & $\begin{array}{l}2.2 \\
3.1\end{array}$ \\
\hline 8 & Salicylic acid & $\begin{array}{c}\text { Tyr299, Asp327, Trp406, Arg526, } \\
\text { Asp542, Phe575, His600 }\end{array}$ & - & - & - \\
\hline 9 & Gallic acid & $\begin{array}{c}\text { Glu182, His 183, Val184, Pro206, Leu540, } \\
\text { Trp552, Gly556 }\end{array}$ & 2 & $\begin{array}{l}\text { Glu182 } \\
\text { His183 }\end{array}$ & $\begin{array}{l}2.1 \\
1.9\end{array}$ \\
\hline 10 & P-coumaric acid & $\begin{array}{c}\text { Tyr299, Asp327, Trp406, Trp441, } \\
\text { Arg526, His600 }\end{array}$ & 1 & His600 & 3.0 \\
\hline 11 & $\begin{array}{l}\text { Protocatechuic } \\
\text { acid } \\
\end{array}$ & $\begin{array}{c}\text { Tyr299, Asp327, Trp441, Arg526, } \\
\text { Asp542, Phe575, His600 }\end{array}$ & 1 & Arg526 & 3.1 \\
\hline 12 & Ferulic acid & $\begin{array}{l}\text { Asp203, Tyr299, Asp327, Trp406, } \\
\text { Trp441, Trp539, Asp542, His600 }\end{array}$ & - & - & - \\
\hline 13 & Sinapic acid & $\begin{array}{c}\text { Tyr299, Asp327, Phe450, Phe575, } \\
\text { His600 }\end{array}$ & 1 & His600 & 2.9 \\
\hline 14 & Vanillic acid & $\begin{array}{c}\text { Tyr299, Ile364, Trp406, Trp539, Asp542, } \\
\text { Phe575, His600 }\end{array}$ & - & - & - \\
\hline 15 & Robustaflavone & $\begin{array}{c}\text { Tyr299, Arg334, Trp406, Trp441, Arg526, } \\
\text { Trp539, Asp542, Phe575, Arg598, } \\
\text { His600, Gln603 }\end{array}$ & - & - & - \\
\hline 16 & Acarbose (control) & $\begin{array}{c}\text { Asp203, Tyr299, Asp327, Ile364, Trp406, } \\
\text { Asp443, Phe450, Asp542, Phe575, } \\
\text { Gln603 }\end{array}$ & 3 & $\begin{array}{l}\text { Asp327 } \\
\text { Asp443 } \\
\text { Asp542 } \\
\end{array}$ & $\begin{array}{l}2.1 \\
1.9 \\
2.3 \\
\end{array}$ \\
\hline
\end{tabular}

Based on the results in Table 2, myricetin formed only one hydrogen bond with Asp327 of the AG enzyme with 2.0 Angstrom $(\AA)$ - bond distance compared to acarbose, which formed three hydrogen bonds with AG enzyme, and the residues that formed the hydrogen bonds were Asp327, Asp443, and Asp542 with bond distance $2.1,1.9$ and $2.3 \AA$, respectively. Hydrogen bond distances for both AG-myricetin complex and AG-acarbose complex were in the range of the favourable length which are lower than $3.0 \AA$ [11]. Thus, the interaction was assumed to be stable for both complexes. The hydrogen bond interaction of both complexes and the interacting residues were illustrated in Figure 6 below. 


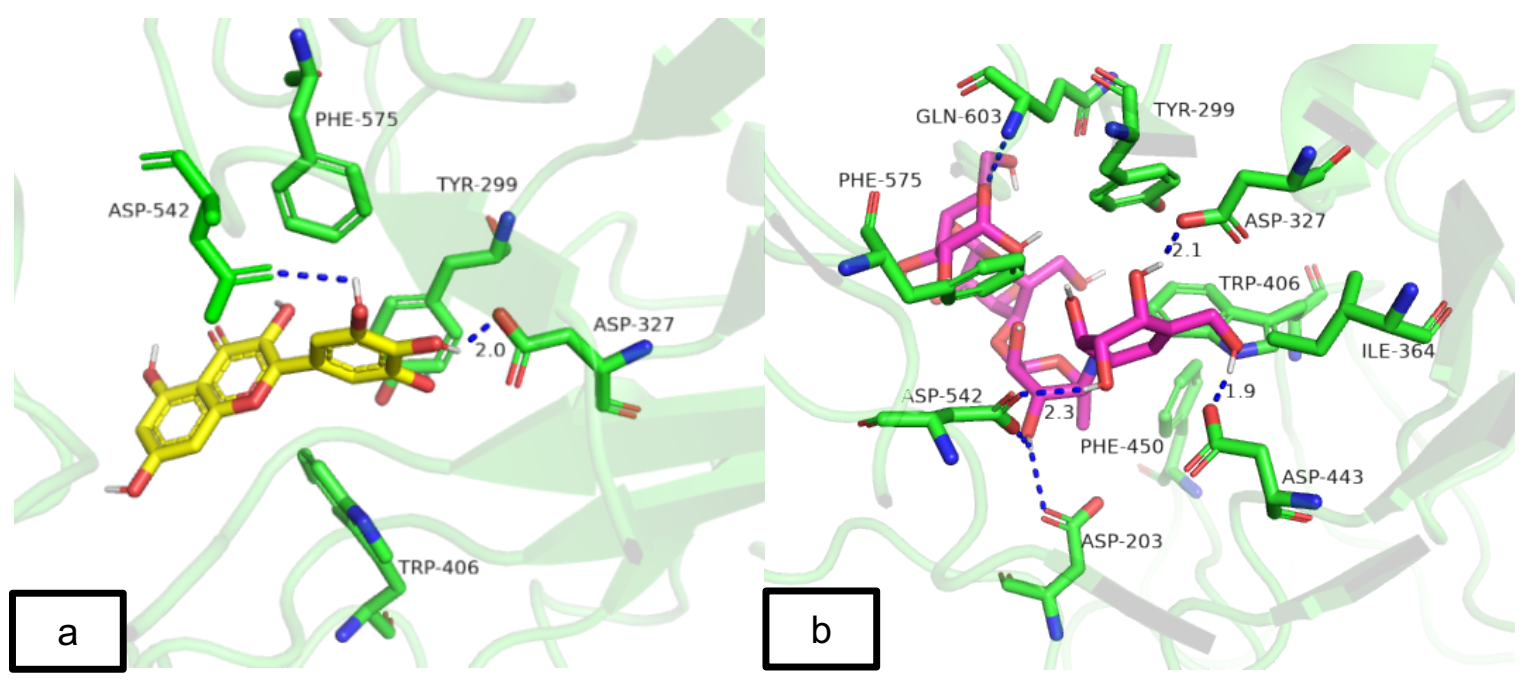

Figure 6. Hydrogen bond formation and interacting residues of AG enzyme with (a) myricetin and (b) acarbose respectively from AutoDock analysis and viewed in PyMOL. A blue dash presents the hydrogen bond. Interacting residues of (a) AG enzyme and myricetin and (b) AG enzyme and acarbose are shown in stick representation. (Colour code: green = carbon $C$ atom of $A G$ enzyme residue, yellow $=\mathrm{C}$ atom of myricetin, magenta $=\mathrm{C}$ atom of acarbose, grey $=$ hydrogen $\mathrm{H}$ atom, red $=$ oxygen $\mathrm{O}$ atom, blue $=$ nitrogen $\mathrm{N}$ atom).

However, the visualisation using LigPlot software showed a different number of hydrogen bond formation as compared to AutoDock v4.2 software. Based on the analysis from LigPlot software, AG-myricetin formed only one hydrogen bond with amino acid residue Asp203 meanwhile AG-acarbose formed six hydrogen bonds with residues Asp203, Asp327, Trp406, Asp443, Asp542 and GIn603 as shown in Figure 7 with green-labelled residues. According to Klvana [16], the different number of hydrogen bond formation was observed using the different software because of its cut off values and angle for detection of hydrogen bond. Therefore, it is crucial to set a similar hydrogen bond cut off values of software to detect an equal number of hydrogen bond formation.

Besides, the molecular docking analysis revealed the interacting residues of AG with each compound. The residues that interacted with myricetin and acarbose were shown in Figure 6 . From the analysis, Tyr299, Asp327, Trp406, Asp542 and Phe575 were main residues that interacted with both ligands, which showed that myricetin has the potential as a candidate for antidiabetic drugs.

\section{Hydrophobic Interaction of AG enzyme and polyphenol compounds}

Another parameter that facilitates the binding interaction of AG binding residue with the polyphenol compounds was the hydrophobic interaction. To analyse the hydrophobic interaction, AG-myricetin complex and AG-acarbose complex were saved in PDB file format. This PDB file input was open in LigPlot software which can generate the schematic 2-D image of the complex binding interaction, including hydrogen bond and hydrophobic interaction automatically [30]. Residues that involved with the formation of hydrogen bond were labelled in green colour. Besides, the hydrophobic interaction was shown as the spokes radiated from an arc that represented residues of protein towards the contacted atom of the ligand. The spokes from the contacted ligand atom were also radiating back towards the residues of the protein [30].

From the analysis using LigPlot software, AG-myricetin complex had nine hydrophobic interactions that contacted with myricetin. It was observed that nine residues of $A G$ enzyme that involved in hydrophobic contact were Asp203, Tyr299, Asp327, Ile364, Trp406, Trp441 Phe450, Asp542 and Phe575 as shown in Figure 7(a). For AG-acarbose complex, 12 residues formed the hydrophobic interaction with acarbose via Asp203, Tyr299, Asp327, Ile364, Trp406, Asp443, Met444, Phe450, Asp542, Phe575, Glu603 and Tyr605. The schematic diagram of the AG-acarbose complex binding is shown in Figure 7(b). From 12 residues that formed hydrophobic interactions, three residues were involved in hydrogen bond formation between the binding residues and acarbose which were Asp327, Asp443 and Asp542. According to Nurul lilani [22], the size of the compound could affect the stability of the protein-ligand complex. Therefore, AG-myricetin complex was more stable than that of AG-acarbose complex although AG- 
acarbose complex has formed 12 hydrophobic interactions. It was due to the size of acarbose which was larger than myricetin as shown in Figure 7.
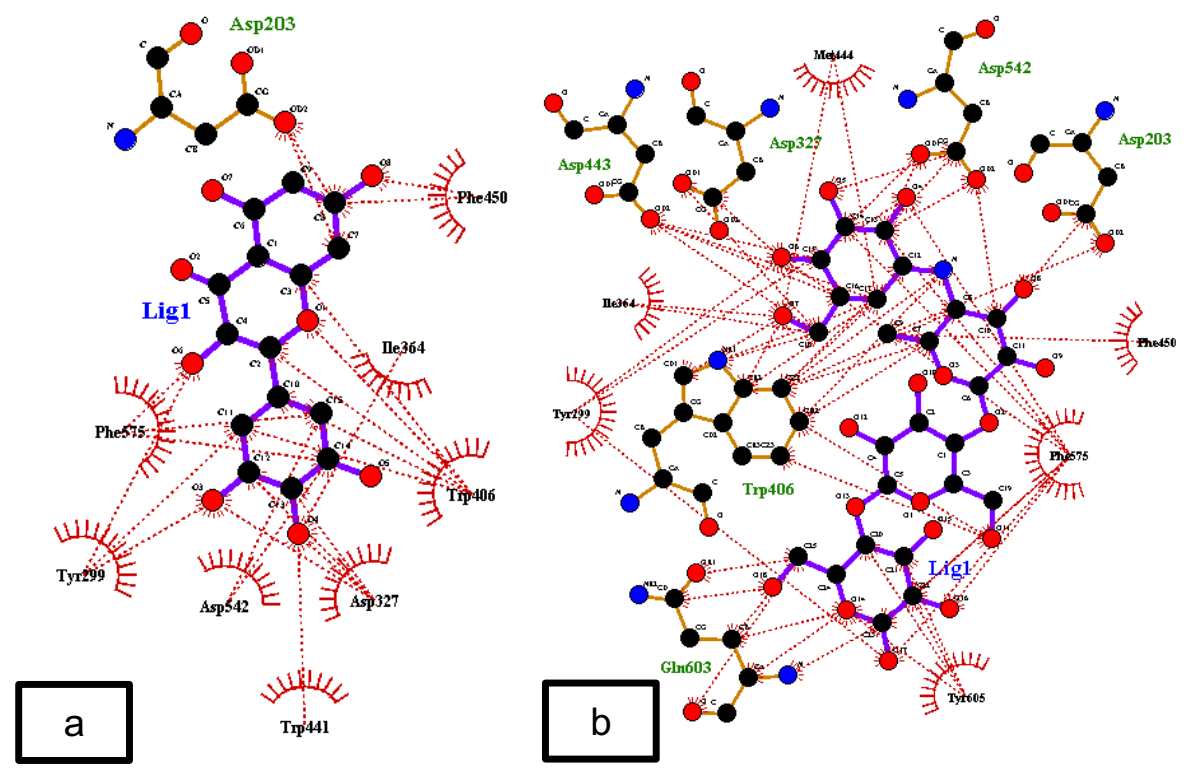

Figure 7. Schematic diagram of AG enzyme residues that formed hydrophobic interaction with (a) myricetin and (b) acarbose respectively illustrated by LigPlot software. (Representation: Lig1 in (a) = myricetin, Lig1 (b) = acarbose, red arc with radiated spokes = residues that involved in hydrophobic interaction, red dotted line $=$ hydrophobic interaction, green-labelled residue $=$ residue that involved in hydrogen bond formation).

\section{Molecular Docking Analysis of DPP-4 Enzyme with Polyphenol Compounds}

Similar to AG enzyme, all the selected polyphenol compounds and sitagliptin were successfully docked at the targeted binding sites of the DPP-4 enzyme. The results of the molecular docking for each combination that formed a complex with DPP-4 enzyme were summarized in Table 3 with their corresponding binding energy values. In Table 4, it stated the results of the hydrogen bond formation and the interacting residues of DPP-4 with each polyphenol compound and sitagliptin.

\section{Binding interaction of DPP-4 enzyme with polyphenol compounds} Based on the molecular docking of polyphenol compounds with DPP-4 enzyme, all complexes had the negative binding energy values as shown in Table 3 which indicated that all the ligand have the potential to bind to both enzymes with different binding affinity. Robustaflavone showed the lowest binding energy value which was $-9.0 \mathrm{kcal} / \mathrm{mol}$; meanwhile, both $\rho$-coumaric acid and protocatechuic acid showed the highest binding energy value, which was $-5.6 \mathrm{kcal} / \mathrm{mol}$. The highest binding energy indicated that $\rho-$ coumaric acid and protocatechuic acid had the lowest binding affinity towards the DPP-4 enzyme. Therefore, robustaflavone had the greatest binding affinity towards the DPP-4 enzyme since the binding energy was the lowest. However, the binding energy value for sitagliptin, a commercial DPP-4 inhibitor that acted as control was lower than that of robustaflavone, which was $-9.2 \mathrm{kcal} / \mathrm{mol}$. It indicated that the binding affinity of sitagliptin towards DPP-4 enzyme binding site was greater than robustaflavone. Therefore, the binding interaction of DPP-4-sitagliptin complex was the strongest; hence it is the most favourable ligand for DPP-4 enzyme to exhibit the greatest inhibitory effect. All the selected natural polyphenol compounds were unable to surpass the binding affinity of sitagliptin towards the binding site of the DPP-4 enzyme, which means that sitagliptin is the best binder. However, robustaflavone was predicted to bind to DPP-4 enzyme with higher binding energy comparable to sitagliptin, which suggested that it may potentially be a good drug candidate against DPP-4 enzyme. 
Table 3. Binding energy of DPP-4 enzyme with 15 polyphenol compounds and sitagliptin from the lowest to the highest value.

\begin{tabular}{ccc}
\hline No. & Polyphenol compounds & Binding energy $(\mathrm{kcal} / \mathrm{mol})$ \\
\hline 1 & Robustaflavone & -9.0 \\
\hline 2 & Catechin & -8.0 \\
\hline 3 & Apigenin & -7.9 \\
\hline 4 & Kaemferol & -7.9 \\
\hline 5 & Myricetin & -7.9 \\
\hline 6 & Quercetin & -7.8 \\
\hline 7 & Genistein & -7.7 \\
\hline 8 & Caffeic acid & -6.0 \\
\hline 9 & Salicylic acid & -6.0 \\
\hline 10 & Vanillic acid & -5.9 \\
\hline 11 & Sinapic acid & -5.9 \\
\hline 12 & Ferullic acid & -5.7 \\
\hline 13 & Gallic acid & -5.7 \\
\hline 14 & P-coumaric acid & -5.6 \\
\hline 15 & Protocatechuic acid & -5.6 \\
\hline 16 & Sitagliptin (control) & -9.2 \\
\hline
\end{tabular}

\section{Hydrogen bond formation between DPP-4 enzyme and polyphenol compounds}

Table 4 showed the number of hydrogen bond formation and the interacting residues for each complex that were analysed using AutoDock v4.2 and the distance of hydrogen bond formation which was measured using PyMOL.

In the molecular docking simulation of DPP-4 enzyme with robustaflavone, the binding interaction of the complex involved the formation of one hydrogen bond with residue Val546 at 2.3 Angstrom $(\AA)$. The bond length was within the favourable range which indicated that the hydrogen bond formation was favourable. Besides, there were 11 residues of DPP-4 enzyme that interacted with robustaflavone which were Glu205, Glu206, Val207, Ser209, Phe357, Arg358, Val546, Tyr547, Gly628, Trp629, Tyr662 as shown in Figure 8.

Meanwhile, the binding interaction of DPP-4 enzyme and sitagliptin formed no hydrogen bond as was analysed using AutoDock v4.2. As there was no hydrogen bond formation, the blue dash in Figure 9 indicated that there were other polar interactions involved in the binding of DPP-4-sitagliptin complex such as Van Der Waal interaction. Also, there were only seven residues that formed the interaction with sitagliptin which were Tyr547, Trp629, Ser630, Tyr631, Val656, Tyr662 and Tyr666 as shown in Figure 9.

However, it was observed that robustaflavone formed four hydrogen bonds with the binding residues of DPP-4 enzyme which were Glu205, Val207, Arg358 and Val546 as shown in Figure 10(a). As for sitagliptin, it was only hydrogen bond bound with one residue, Tyr547 as shown in Figure 10(b). According to Kalhotra et al. [15], Tyr547 was one of the target drug regions for DPP-4 enzyme. Thus, it indicated that Tyr547 was the most important binding residue for inhibitory activity of DPP-4 enzyme. Although robustaflavone was interacted with more residues and formed a greater number of hydrogen bonds with DPP-4 enzyme, sitagliptin was the most favourable towards the binding site of the DPP-4 enzyme because of the interaction with Tyr547. 
Table 4. Hydrogen bond formation and interacting residues of DPP-4 enzyme with each polyphenol compound analysed by Autodock v4.2 and PyMOL

\begin{tabular}{|c|c|c|c|c|c|}
\hline No. & Polyphenol compounds & Interacting residues & $\begin{array}{l}\text { No. of } \mathrm{H}- \\
\text { bond }\end{array}$ & $\begin{array}{l}\text { H-bonded } \\
\text { residue }\end{array}$ & $\begin{array}{l}\text { Distance } \\
\qquad(\AA)\end{array}$ \\
\hline 1 & Robustaflavone & $\begin{array}{c}\text { Glu205, Glu206, Val207, Ser209, } \\
\text { Phe357, Arg358, Val546, Tyr547, } \\
\text { Gly628, Trp629, Tyr662 }\end{array}$ & 1 & Tyr547 & 2.3 \\
\hline 2 & Catechin & $\begin{array}{c}\text { Arg125, Glu205, Ser209, Phe357, } \\
\text { Tyr547, Ser630, Tyr631, Tyr662, } \\
\text { Tyr666, Arg669 }\end{array}$ & 1 & Tyr631 & 3.2 \\
\hline 3 & Apigenin & $\begin{array}{l}\text { Glu206, Ser209, Phe357, Tyr547, } \\
\text { Tyr631, Tyr662, Tyr666, Arg669 }\end{array}$ & 1 & Glu206 & 1.8 \\
\hline 4 & Kaemferol & $\begin{array}{l}\text { Glu206, Ser209, Phe357, Tyr547, } \\
\text { Tyr631, Tyr662, Tyr666, Arg669 }\end{array}$ & 1 & Glu206 & 2.1 \\
\hline 5 & Myricetin & $\begin{array}{c}\text { Glu206, Phe357, Tyr547, Tyr631, } \\
\text { Tyr662, Tyr666 }\end{array}$ & - & - & - \\
\hline 6 & Quercetin & $\begin{array}{l}\text { Arg125, Phe357, Ser630, Val656, } \\
\text { Tyr662, Tyr666, Val711, His740 }\end{array}$ & - & - & - \\
\hline 7 & Genistein & $\begin{array}{l}\text { Glu206, Phe357, Tyr547, Ser630, } \\
\text { Val656, Tyr662, Tyr666, Val711 }\end{array}$ & 1 & Glu206 & 1.8 \\
\hline 8 & Caffeic acid & Glu205, Ser630, Tyr662, Tyr666 & 1 & Glu205 & 2.1 \\
\hline 9 & Salicylic acid & $\begin{array}{c}\text { Glu205, Ser630, Val656, Tyr662, } \\
\text { Tyr666, Val711, His740 }\end{array}$ & - & - & - \\
\hline 10 & Vanillic acid & $\begin{array}{c}\text { Arg125, Tyr547, Tyr631, Tyr662, } \\
\text { Tyr666, His740 }\end{array}$ & 1 & Tyr547 & 2.9 \\
\hline 11 & Sinapic acid & Tyr547, Ser630, Tyr662, Tyr666 & 1 & Tyr662 & 3.2 \\
\hline 12 & Ferullic acid & $\begin{array}{c}\text { Val546, Tyr547, Lys554, Trp629, } \\
\text { Ser630 }\end{array}$ & 1 & Trp629 & 3.1 \\
\hline 13 & Gallic acid & $\begin{array}{c}\text { Arg125, Tyr547, Ser630, Tyr662, } \\
\text { Tyr666, Asn710, Val711 }\end{array}$ & 1 & Tyr547 & 3.0 \\
\hline 14 & P-coumaric acid & Phe357, Tyr547 & - & - & - \\
\hline 15 & Protocatechuic acid & $\begin{array}{l}\text { Arg125, Glu205, Ser630, Tyr631, } \\
\text { Val656, Tyr662, Tyr666, Val711, His740 }\end{array}$ & - & - & - \\
\hline 16 & Sitagliptin (control) & $\begin{array}{c}\text { Tyr547, Trp629, Ser630, Tyr631, } \\
\text { Val656, Tyr662, Tyr666 }\end{array}$ & - & - & - \\
\hline
\end{tabular}




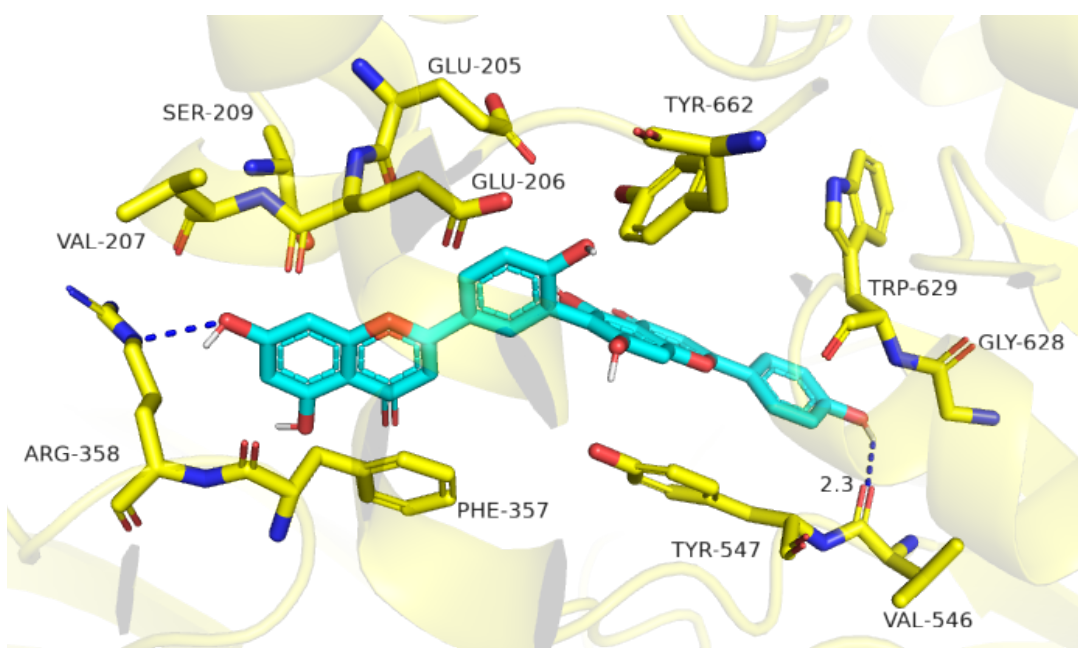

Figure 8: Hydrogen bond formation and interacting residues of DPP-4 enzyme with robustaflavone from AutoDock analysis and viewed in PyMOL. A blue dash presents the hydrogen bond. Interacting residues of DPP-4 enzyme and robustaflavone are shown in stick representation. (Colour code: yellow = $\mathrm{C}$ atom of DPP-4 enzyme residue, blue $=\mathrm{C}$ atom of robustaflavone, grey $=\mathrm{H}$ atom, red $=\mathrm{O}$ atom, blue $=\mathrm{N}$ atom).

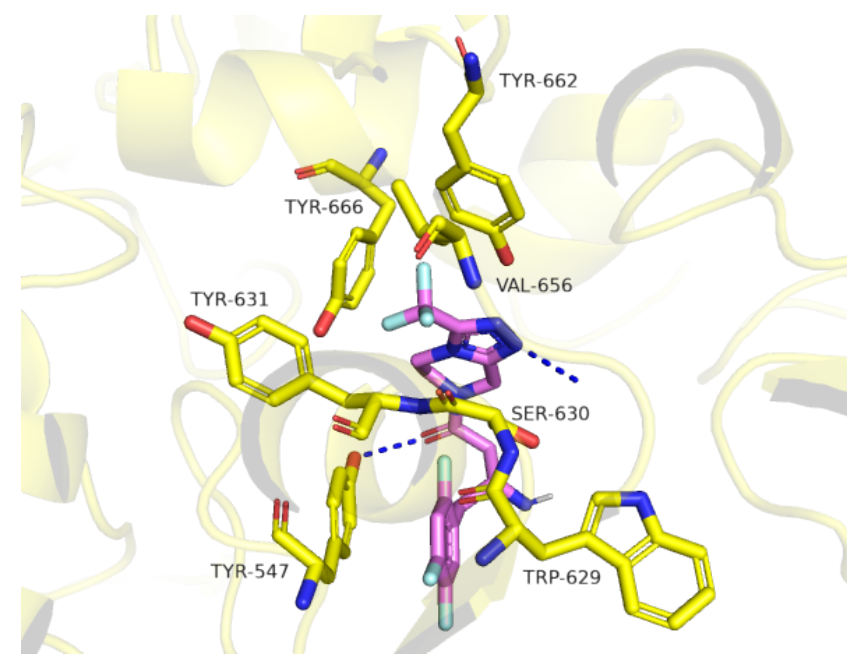

Figure 9. Hydrogen bond formation and interacting residues of DPP-4 enzyme with sitagliptin from AutoDock analysis and viewed in PyMOL. A blue dash presents the hydrogen bond. Interacting residues of DPP-4 enzyme and sitagliptin are shown in stick representation. (Colour code: yellow $=\mathrm{C}$ atom of DPP-4 enzyme residue, light purple $=\mathrm{C}$ atom of sitagliptin, grey $=\mathrm{H}$ atom, red $=\mathrm{O}$ atom, blue $=\mathrm{N}$ atom, light blue $=$ fluorine $(F)$ atom $)$.

\section{Hydrophobic Interaction of DPP-4 enzyme and polyphenol compounds}

The binding of the DPP-4 enzyme with polyphenol compounds was also facilitated by hydrophobic interaction. It was found that DPP-4-robustaflavone complex had 11 hydrophobic interactions that contacted with robustaflavone. The residues of the DPP-4 enzyme involved in hydrophobic contact were Glu205, Glu206, Val207, Ser209, Phe357, Arg358 Val546, Tyr547, Gly628, Trp629, Ser630 as shown in Figure 10(a). Among these residues, Glu205, Val207, Arg358 and Val546 were known to have participated in the formation of hydrogen bond in which contributed to the stabilisation of the complex 
binding interaction.

As for DPP-4-sitagliptin complex, the binding of a complex involved nine hydrophobic interactions with amino acid residues Arg125, Tyr547, Ser630, Tyr631, Tyr656, Tyr629, Tyr662, Tyr666 and Val711 as illustrated in Figure 10(b). Sitagliptin was tightly bound to amino acid Tyr547 of the DPP-4 enzyme by forming hydrogen bond and hydrophobic interaction which caused a high binding affinity between the complexes. The interaction of the complex was also facilitated by a strong hydrophobic contact with Ser630 resulted into a significant binding of sitagliptin on DPP-4 enzyme binding site. Other than Tyr547, Kalhotra et al. [15] stated that Ser630 was another important druggable region for DPP-4 enzyme, which could be assisted in complex binding on an excellent inhibition activity.

As for comparison for both robustaflavone and sitagliptin in terms of the three parameters above, sitagliptin was more stabilise than robustaflavone because the binding energy was the lowest and it formed a strong interaction with the druggable region on DPP-4 enzyme. Furthermore, robustaflavone was a larger substrate as compared to sitagliptin hence sitagliptin was the most favourable as a DPP-4 inhibitor for the treatment of T2DM.
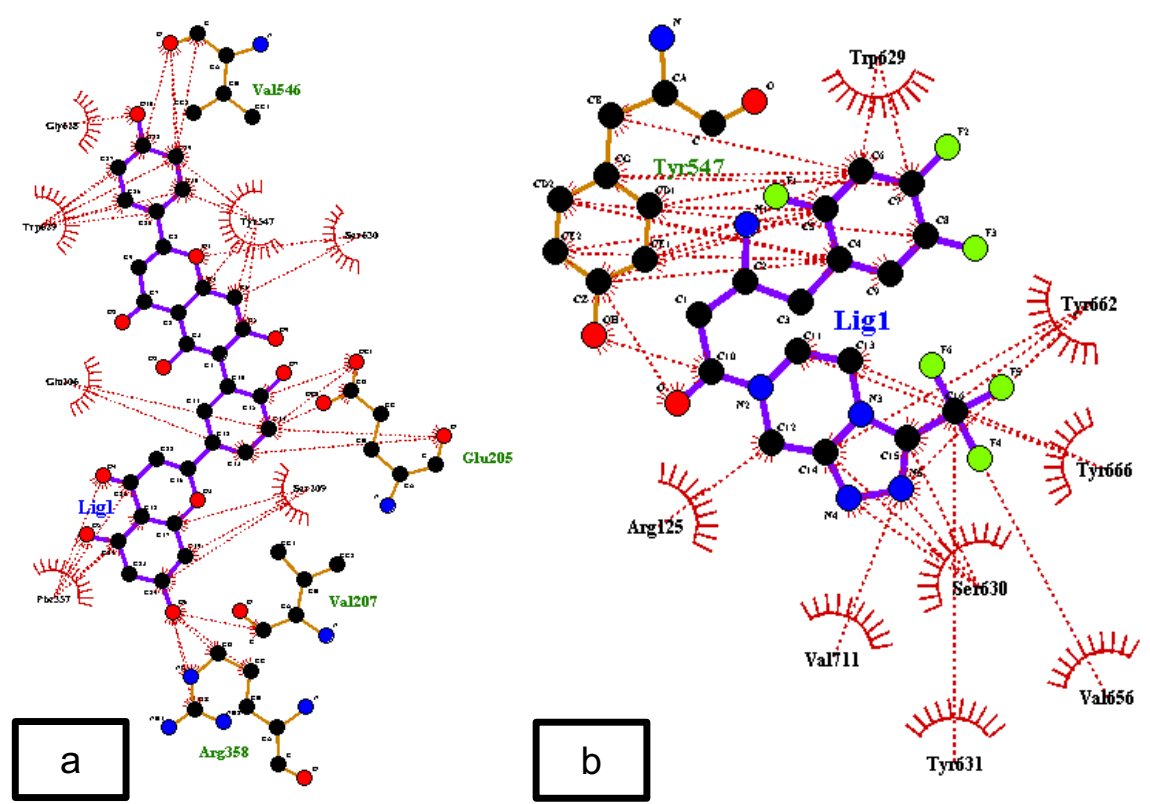

Figure 10. Schematic diagram of DPP-4 enzyme residues that interact with (a) robustaflavone and (b) sitagliptin respectively, visualised by LigPlot software. (Representation: Lig1 in (a) = robustaflavone, Lig1 in (b) = sitagliptin, red arc with radiated spokes = residues that involved in hydrophobic interaction, red dotted line $=$ hydrophobic interaction, green-labelled residues $=$ residues that involved in hydrogen bond formation).

\section{Conclusions}

In conclusion, our molecular docking simulation results revealed the binding interaction between natural polyphenol compounds from $A$. occidentale with AG and DPP-4 enzymes. Our results suggest that myricetin to be the best compound that may interact with the AG enzyme with comparable binding energy to acarbose, and could potentially exhibit the inhibitory effect for the AG enzyme. The strong interaction between myricetin and AG enzyme was facilitated by the formation of hydrogen bonds and hydrophobic contacts. For DPP-4 enzyme, this study suggests that sitagliptin to be the most favourable compound to inhibit the DPP-4 enzyme activity where it formed a strong interaction with the druggable region on DPP4 enzyme compared to robustaflavone. However, further studies are needed to investigate the dynamic interaction of the protein-ligand interactions at atomic level via atomistic molecular dynamics simulations. This study also suggests that myricetin and sitagliptin are the promising compounds that warrant further 
investigation using enzyme inhibition against AG enzyme and DPP-4 respectively to validate its potential inhibition experimentally. Further works are necessary to establish the efficacy and plausible mechanism for medicinal use of this compound. Our study suggests that AG and DPP-4 are the promising enzymes as a target for management of T2DM using polyphenol compounds to be extracted from $A$. occidentale in the future.

\section{Conflicts of Interest}

The author(s) declare(s) that there is no conflict of interest regarding the publication of this paper.

\section{Acknowledgment}

This work is part of a research project, FRGS19-090-0699, supported by the Ministry of Higher Education, Malaysia, and the International Islamic University Malaysia.

\section{References}

[1] Abdullah Thaidi, N. I., Mat Jusoh, H., Ghazali, A. B., Susanti, D., \& Haron, N. (2019). The Effect of Bioactive Polyphenols from Anacardium occidentale Linn. Leaves on Alpha-Amylase and Dipeptidyl Peptidase IV Activities. Indonesian Journal of Chemistry.

[2] Abdullahi, S., \& Olatunji, G. A. (2010). Antidiabetic Activity of Anacardium occidentale in Alloxan - diabetic Rats. Journal of Science and Technology, 30(3), 35-39.

[3] Agius, L. (2008). Targeting Hepatic Glucokinase in Type 2 Diabetes: Weighing the Benefits and Risks. Diabetes, 58(1), 18-20.

[4] Aracelli, de S. L., Md., T. I., Antonio, L. G. J., Joao, M. de C. e S., Marcus, V. O. B. de A., Marcia, F. C. J. P., ... Jose, A. D. L. (2016). Pharmacological properties of cashew (Anacardium occidentale). African Journal of Biotechnology, 15(35), 1855-1863.

[5] Baig, M. H., Ahmad, K., Rabbani, G., Danishuddin, M., \& Choi, I. (2018). Computer Aided Drug Design and its Application to the Development of Potential Drugs for Neurodegenerative Disorders. Current neuropharmacology, 16(6), 740-748.

[6] Baptista, A., Gonçalves, R. V., Bressan, J., \& do Carmo Gouveia Pelúzio, M. (2018). Antioxidant and Antimicrobial Activities of Crude Extracts and Fractions of Cashew (Anacardium occidentale L.), Cajui (Anacardium microcarpum), and Pequi (Caryocar brasiliense C.): A systematic Review. Oxidative Medicine and Cellular Longevity.

[7] Berg, J. M., Tymoczko, J. L. \& Stryer, L. (2002). Biochemistry: Section 1.3, Chemical Bonds in Biochemistry ( $5^{\text {th }}$ ed). New York, NY: W H Freeman 2002.

[8] Chotphruethipong, L., Benjakul, S., \& Kijroongrojana, K. (2019). Ultrasound assisted extraction of antioxidative phenolics from cashew (Anacardium occidentale L.) leaves. Journal of Food Science and Technology.

[9] Dias, C. C. Q., Madruga, M. S., Pintado, M. M. E., Almeida, G. H. O., Alves, A. P. V., Dantas, F. A., ... Soares, J. K. B. (2019). Cashew nuts (Anacardium occidentale L.) decrease visceral fat, yet augment glucose in dyslipidemic rats. PLOS ONE, 14(12).

[10] El-Kabbani, O., Ruiz, F., Darmanin, C., \& Chung, R. P.-T. (2004). Aldose reductase structures: implications for mechanism and inhibition. Cellular and Molecular Life Sciences (CMLS), 61(7-8), 750-762.

[11] Fikrika, H., Ambarsari, L., \& Sumaryada, T. (2016). Molecular Docking Studies of Catechin and Its Derivatives as Anti-bacterial Inhibitor for Glucosamine-6-Phosphate Synthase. IOP Conference Series: Earth and Environmental Science, 31, 012009.

[12] Hebert, L. F., Jr, Daniels, M. C., Zhou, J., Crook, E. D., Turner, R. L., Simmons, S. T., Neidigh, J. L., Zhu, J. S., Baron, A. D., \& McClain, D. A. (1996). Overexpression of glutamine:fructose-6-phosphate amidotransferase in transgenic mice leads to insulin resistance. The Journal of clinical investigation, 98(4), 930-936.

[13] Hubbard, R. E. (2010). Hydrogen Bonds in Proteins : Role and Strength, (February).

[14] Hyun, T. K., Eom, S. H., \& Kim, J. (2014). Molecular docking studies for discovery of plant- derived a glucosidase inhibitors, $7(3), 166-170$.

[15] Kalhotra, P., Chittepu, V. C., Osorio-Revilla, G., \& Gallardo-Velázquez, T. (2019). Discovery of Galangin as a Potential DPP-4 Inhibitor That Improves Insulin-Stimulated Skeletal Muscle Glucose Uptake: A Combinational Therapy for Diabetes. International journal of molecular sciences, 20(5), 1228.

[16] Klvana, M. (2018). Re: The number and distance of $\mathrm{H}$-bond formed between protein-ligand complex varies in 2 different softwares, how it is possible?

[17] Kondo, H., Fujimoto, K.J., Tanaka, S., Deki, H., Nakamura, T. (2015). Theoretical Prediction and Experimental Verification on Enantioselectivity of haloacid dehalogenase L-DEX YL with chloropropionate. Chemical Physics Letters.

[18] Mohammed, A., Kumar, D., \& Rizvi, S. I. (2015). Antidiabetic Potential of Some Less Commonly Used Plants in Traditional Medicinal Systems of India and Africa. Journal of Intercultural Ethnopharmacology, 4(1).

[19] Natarajan, A., Sugumar, S., Bitragunta, S., \& Balasubramanyan, N. (2015). Molecular docking studies of (4Z, 12Z)-cyclopentadeca-4, 12-dienone from Grewia hirsuta with some targets related to type 2 diabetes. BMC Complementary and Alternative Medicine, 15(1). 
[20] National Center for Biotechnology Information. PubChem Database. Phenol, CID=996

[21] Nur Athirah Zabidi , Nur Akmal Ishak, Muhajir Hamid, Siti Efliza Ashari \& Muhammad Alif Mohammad Latif (2021) Inhibitory evaluation of Curculigo latifolia on a-glucosidase, DPP (IV) and in vitro studies in antidiabetic with molecular docking relevance to type 2 diabetes mellitus. Journal of Enzyme Inhibition and Medicinal Chemistry, 36(1), 109-121.

[22] Nurul lilani, A. H. (2015). Affinity of dehalogenase E towards various of haloalkanoic acids. International Islamic University Malaysia, Kuantan.

[23] Okpashi, V. E., Bayim, P. R. B., \& Obi-Abang, M. (2014). Comparative Effects of Some Medicinal Plants: Anacardium occidentale, Eucalyptus globulus, Psidium guajava, and Xylopia aethiopica Extracts in AlloxanInduced Diabetic Male Wistar Albino Rats. Biochemistry Research International.

[24] Rizvi, S. I., \& Mishra, N. (2013). Traditional Indian Medicines Used for the Management of Diabetes Mellitus. Journal of Diabetes Research.

[25] Ross, I. A. (2001). Anacardium occidentale. Medicinal Plants of the World. Humana Press. Totowa, NJ. (2). 43-45.

[26] Salehi, Gültekin-Özgüven, Kırkın, Özçelik, Morais-Braga, Carneiro, Bezerra, et al. (2019). Anacardium Plants: Chemical, Nutritional Composition and Biotechnological Applications. Biomolecules, 9(9), 465.

[27] Schulze-Kaysers, N., Feuereisen, M. M., \& Schieber, A. (2015). Phenolic compounds in edible species of the Anacardiaceae family - a review. RSC Advances, 5(89), 73301-73314.

[28] Shen, W., \& Lu, Y. H. (2013). Molecular docking of citrus flavonoids with some targets related to diabetes. Bangladesh Journal of Pharmacology, 8(2), 156-170.

[29] Thallapally, P. K., \& Nangia, A. (2001). A Cambridge Structural Database analysis of the C - H ... Cl interaction : $\mathrm{C}-\mathrm{H} \ldots \mathrm{Cl} 2$ and $\mathrm{C}-\mathrm{H} \ldots \mathrm{Cl}-\mathrm{M}$ often behave as hydrogen bonds but $\mathrm{C}-\mathrm{H} \ldots \mathrm{Cl}-\mathrm{C}$ is generally a van der Waals interaction, 1-6.

[30] Wallace, A. C., Laskowski, R. A., \& Thornton, J. M. (1995). LIGPLOT: a program to generate schematic diagrams of protein-ligand interactions Clean up structure, 8(2), 127-134.

[31] World Health Organization. (2020). Diabetes. Retrieved from https://www.who.int/news-room/factsheets/detail/diabetes

[32] Yuan, H., Ma, Q., Ye, L., \& Piao, G. (2016). The Traditional Medicine and Modern Medicine from Natural Products. Molecules, 21. 